\title{
FBP1 expression is associated with basal-like breast carcinoma
}

\author{
LEI SHI ${ }^{1}$, CHUNBO ZHAO $^{2}$, HAIHONG PU $^{3}$ and QINGYUAN ZHANG ${ }^{3}$ \\ ${ }^{1}$ Department of Radiation Oncology, The Fourth Hospital, Harbin Medical University, Harbin, \\ Heilongjiang 150001; Departments of ${ }^{2}$ Radiation Oncology and ${ }^{3}$ Oncology, The Third \\ Hospital, Harbin Medical University, Harbin, Heilongjiang 150080, P.R. China
}

Received October 5, 2015; Accepted December 9, 2016

DOI: $10.3892 / \mathrm{ol} .2017 .5860$

\begin{abstract}
The present study aimed to investigate the value of liver fructose 1,6-bisphophatase (FBP1) and hypoxia-inducible factor- $1 \alpha$ (HIF-1 $\alpha)$ in the molecular subtyping of breast carcinoma. Tissue obtained from 60 surgical specimens from patients with breast carcinoma underwent immunohistochemical staining for cytokeratin 5/6, HIF-1 $\alpha$ and FBP1. The variation in the expression levels of these markers and clinicopathological factors were compared between molecular subtypes. In addition, disease-free survival was compared between basal-like and luminal breast carcinoma, according to differing expression levels of HIF-1 $\alpha$ and FBP1. The results revealed that HIF-1 $\alpha$ expression was detectable in 20/60 $(33.3 \%)$ of the breast carcinoma cases, and was positively associated with lymph node metastasis $(\mathrm{P}=0.007)$. HIF-1 $\alpha$-positive patients exhibited a shorter disease-free survival, compared with HIF-1 $\alpha$-negative patients with invasive breast cancer. The expression levels of FBP1 were positive in 33/60 tumor tissues (55\%; $\mathrm{P}<0.001)$, and FBP1 expression was associated with nuclear grade $(\mathrm{P}=0.017)$ and tumor stage $(\mathrm{P}=0.012)$. In breast carcinoma, HIF-1 $\alpha$ expression levels were significantly negatively correlated with FBP1 levels $(r=-0.711 ; \mathrm{P}<0.001)$. Cox regression analysis identified FBP1 and tumor size as independent prognostic factors. Therefore, the present study demonstrated that patients with basal-like breast carcinoma exhibited lower levels of FBP1 expression in tumor tissues, compared with patients with luminal type breast cancer, and that low or absent expression levels of FBP1 may be associated with reduced disease-free survival.
\end{abstract}

\section{Introduction}

Hypoxia is an established characteristic of high-grade breast tumors (1) and is considered to be associated with increased

Correspondence to: Dr Qingyuan Zhang, Department of Oncology, The Third Hospital, Harbin Medical University, 150 Haping Road, Nangang, Harbin, Heilongjiang 150080, P.R. China

E-mail: qingyuanzhang01@tom.com

Key words: breast carcinoma, basal-like, luminal, hypoxia-inducible factor-1 $\alpha$, fructose 1,6-bisphophatase therapy resistance, poor disease-free survival (DFS) and a high rate of metastasis (2-6). The hypoxia-inducible factor family members are key elements in the hypoxic signaling pathway (7). Intratumoral hypoxia is caused by abnormal microvasculature in proliferating tumor tissues, and may induce proteomic changes, allowing tumors to adapt to or overcome the nutrient-deprived state (8-11). This is accomplished with enhanced glycolysis, inhibition of apoptosis and the increased expression of certain proteins that are associated with tumor invasiveness $(12,13)$. HIF-1 $\alpha$ is a cytoplasmic protein that is involved in the cellular response to alterations in oxygen levels, and is important in the expression of hypoxia-inducible genes (14). HIF-1 $\alpha$ protein is expressed and continuously degraded under normoxic conditions due to binding to the von Hippel-Lindau protein in the cytoplasm (15). Under hypoxic conditions, HIF-1 $\alpha$ subunits translocate to the nucleus and heterodimerize with HIF-1 $\beta$ subunits (2). HIF-1 $\alpha$ overexpression and signaling result in adaptive responses, which may enhance vascular endothelial growth factor-mediated angiogenesis in order to meet the energy requirements of the cell (16). Basal-like breast carcinoma differs from the luminal type due to its negative expression of certain hormone receptors and associated genes, and positive expression of cytokeratin 5/6 (CK5/6) (17). Basal-like breast carcinoma lesions frequently exhibit increased hypoxia and a high tumor grade $(18,19)$, which triggers further necrosis and aggressive behavior, as compared with the luminal type (20), and tumor necrosis is considered a consequence of hypoxia $(11,21)$. The current study hypothesized that these tumors may have altered hypoxic responses and metabolic requirements.

Another important mechanism underlying necrosis is a lack of gluconeogenesis in the tumor cell environment, in which cells grow at a rate that outstrips the rate of energy production (22). Upregulation of the HIF-1 $\alpha$ gene and its downstream target genes may result in glycolysis (23). Fructose 1,6-bisphophatase is a rate-limiting enzyme that functions during gluconeogenesis $(24,25)$ to convert fructose-1,6-bisphophate (FBP1) into fructose-6-phosphate and inorganic phosphates. FBP1 is recognized as a gluconeogenesis regulatory enzyme $(24,26)$. Previous studies have indicated that an increase in FBP1 expression levels predicts an improved outcome across a spectrum of neoplastic diseases, including kidney $(27,28)$, stomach and lung carcinoma (29). These results suggest that the epigenetic regulation of FBP1 is important in modulating glucose metabolism in cancer. Li et al (28) identified that FBP1 limits 
clear-cell renal cell carcinoma proliferation by inhibiting the function of nuclear HIF via a direct interaction with the HIF inhibitory domain.

The present study hypothesized that FBP1 may possess anticancer properties in breast cancer cell lines, potentially due to the suppression of HIF-1 $\alpha$ expression levels. Therefore, the expression levels of HIF-1 $\alpha$ and FBP1 were investigated using immunohistochemical analysis in human luminal and basal-like breast cancer tissues. Subsequently, the association between clinical characteristics and the expression levels of HIF-1 $\alpha$ and FBP1 was analyzed.

\section{Materials and methods}

Patient selection and clinicopathological analysis. Tumor tissue samples from patients with breast cancer were obtained by resection between September 2004 and September 2008 at The Tumor Hospital, Harbin Medical University (Harbin, China). Paraffin-embedded tissue samples were obtained retrospectively from the archives of the Department of Pathology. Informed patient consent for the anonymous use of the remainder of tumor material was obtained as part of the standard treatment agreement. All tissue specimens had been fixed for $\leq 24 \mathrm{~h}$ in neutral buffered $4 \%$ formaldehyde and classified according to the World Health Organization (30). All patients had operable breast carcinoma and were not diagnosed with metastatic disease at the time of presentation. Information regarding patient characteristics, including patient age at initial diagnosis, tumor size, nuclear grade, histology and nodal status, were obtained from the clinical and pathological records. The mean age of the patients was 53 years (range, $25-70)$. In total, $43 \%$ of the tumors were invasive ductal of no specific type, $37 \%$ were invasive lobular carcinoma and $20 \%$ were of other histological classifications. Histological classification revealed 38 luminal type and 26 basal-like type cases. Tumors were graded using the Elston criteria, as grade 1 $(n=22)$, grade $2(n=22)$ or grade $3(n=20)(31)$. Nodal disease was present in $55 \%$ of patient tissue samples. None of the patients received preoperative chemotherapy, hormonal treatment or radiotherapy. Adjuvant systemic treatment (chemotherapy for premenopausal and tamoxifen for postmenopausal patients) was administered according to the established guidelines of the National Comprehension Cancer Network (32). Estrogen receptor (ER) status was determined routinely by immunohistochemistry (33). The follow-up period was 16-84 months (mean, 60) for surviving patients. During follow-up, 42 patients developed loco-regional recurrence $(n=9)$ or distant metastases $(n=33)$, leading to a total of 33 disease-associated mortalities. Four additional patients succumbed to unrelated conditions and were removed from the survival analysis. Approval for the analyses conducted in the present study was received from The Ethics Committee of Harbin Medical University.

DFS was evaluated as the time from the date of the initial curative surgery to the date of the first loco-regional or systemic relapse, or mortality in the absence of relapse. Immunohistochemistry was performed on $3-\mu \mathrm{m}$ thick tissue sections. Table I presents all antibodies, dilutions, antigen-retrieval methods, incubation times and methods of detection used. Tissue sections were deparaffinized with xylene and rehydrated with ethanol solutions. The optimal primary antibody incubation times and concentrations were determined via serial dilution for each immunohistochemical assay using an identically fixed and embedded tissue block. The slides were counterstained with Harris hematoxylin. The degree of staining was determined by two pathologists using a multiview light microscope.

Immunohistochemical staining. Tumor sections were placed in ice-cold $4 \%$ formalin containing a phosphatase-inhibiting reagent (4\% paraformaldehyde for 24-48 h), dehydrated using ethanol $(100,95,85$ and $75 \%)$, paraffin embedded, and stained (Table I). Samples were incubated with $3 \%$ hydrogen peroxide solution (Sinopharm Chemical Reagent Co., Ltd., Shanghai, China) at room temperature for $15 \mathrm{~min}$ to eliminate endogenous peroxidase activity. Samples were washed with PBS three times. Samples were blocked with goat serum (Hyclone, GE Healthcare Life Sciences, Logan, UT, USA) for $60 \mathrm{~min}$ at room temperature. Samples were subsequently incubated with the primary antibodies presented in Table I. Samples were washed with PBS three times. Samples were incubated with biotin-labeled secondary anti-rabbit antibody (cat. no. ab6721; dilution, 1:200; Abcam, Cambridge, UK) at $37^{\circ} \mathrm{C}$ for $60 \mathrm{~min}$. Samples were washed with PBS three times. Samples were incubated with horseradish peroxidase-labeled chain mildew avidin or alkaline phosphatase (ZSGB-Biology Co., Ltd., Beijing, China) at $37^{\circ} \mathrm{C}$ for $30 \mathrm{~min}$. Samples were washed with PBS three times. Samples were stained with diaminobenzidine (ZSGB-Biology Co., Ltd.) for between 3 and $10 \mathrm{~min}$ in darkness and observed using an inverted microscope, magnification, $\mathrm{x} 4-10$. Samples were washed twice with $\mathrm{H}_{2} \mathrm{O}$. Samples were counterstained with hematoxylin (Western Biology Co., Ltd., Chongqing, China) for $1 \mathrm{~min}$. Samples were washed with $\mathrm{H}_{2} \mathrm{O}$. Samples were dehydrated in an ascending alcohol (Sinopharm Chemical Reagent Co., Ltd.) series of 75, 85, 95 and $100 \%$ for $3 \mathrm{~min}$. Xylene (Sinopharm Chemical Reagent Co., Ltd.) was used to deparaffinize the specimens for $3 \mathrm{~min}$. Neutral gum (ZSGB-Biology Co., Ltd.,) was used to seal the samples.

Evaluation of immunohistochemical staining. All immunohistochemical markers (HIF-1 $\alpha$, FBP1 and CK5/6) were assessed using light microscopy. Scoring of the immunostained slides was performed according to the proportion of tumor cells that exhibited nuclear (HIF-1 $\alpha$ and FBP1) staining. HIF-1 $\alpha$ staining was considered positive when an immunohistochemical signal was observed in $\geq 5 \%$ of nuclei, according to the cut-off value previously utilized by Bos et al (34). FBP1 expression was considered positive when $>25 \%$ of the tumor cell nuclei were stained.

Molecular classification of breast cancer according to immunohistochemistry. According to the results of immunohistochemistry, breast cancer types were classified into basal-like type (CK5/6 positive and/or EGFR positive) or luminal type [ER positive and/or progestin receptor (PR) positive] (30). The expression levels of ER and PR were designated as positive when $\geq 1 \%$ of the tumor nuclei exhibited positive staining. Human epidermal growth factor receptor-2 (HER2) expression levels were also classified using immunohistochemical staining based on the HercepTest ${ }^{\mathrm{TM}}$ (Dako; Agilent 
Table I. Antibodies and experimental conditions for immunohistochemistry.

\begin{tabular}{llllll}
\hline Catalog number & Specificity & \multicolumn{1}{c}{ Source } & Dilution & Antigen-retrieval method & Incubation time \\
\hline ab85886 & HIF-1 $\alpha$ & Abcam (Cambridge, UK) & $1: 500$ & Microwave, citrate buffer, 95 C, 30 min & $30 \mathrm{~min}, \mathrm{RT}$ \\
ab196556 & FBP1 & Abcam & $1: 200$ & Microwave, citrate buffer, $95^{\circ} \mathrm{C}, 20 \mathrm{~min}$ & $\mathrm{Overnight,4}{ }^{\circ} \mathrm{C}$ \\
ab86974 & CK5/6 & Abcam & $1: 50$ & Pepsin enzyme, RT, 30-60 sec & $30 \mathrm{~min}, \mathrm{RT}$
\end{tabular}

HIF-1 $\alpha$, hypoxia-inducible factor-1 $\alpha$; FBP1, liver fructose-1,6-bisphosphatase; CK5/6, cytokeratin 5/6; RT, room temperature.

Table II. Patient characteristics in various types of breast cancer.

\begin{tabular}{|c|c|c|c|c|}
\hline Characteristics & All $(n=60)$ & Luminal $(n=36)$ & Basal-like $(n=24)$ & P-value \\
\hline Mean age, years & $53 \pm 8.7(25-70)$ & $55 \pm 9.0(30-68)$ & $49 \pm 9.0(25-70)$ & 0.932 \\
\hline Menopausal status & & & & 0.312 \\
\hline Premenopausal & 22 & $15(68.2)$ & $7(31.8)$ & \\
\hline Postmenopausal & 38 & $21(55.3)$ & $17(44.7)$ & \\
\hline Stage & & & & 0.098 \\
\hline I & 20 & $14(70.0)$ & $6(30.0)$ & \\
\hline II & 28 & $17(60.7)$ & $11(39.3)$ & \\
\hline III & 12 & $5(41.7)$ & $7(58.3)$ & \\
\hline T stage & & & & 0.132 \\
\hline $\mathrm{T} 1$ & 30 & $24(80.0)$ & $6(20.0)$ & \\
\hline $\mathrm{T} 2$ & 18 & $8(44.4)$ & $10(55.6)$ & \\
\hline T3 & 12 & $4(33.3)$ & $8(66.7)$ & \\
\hline Nodal status & & & & 0.050 \\
\hline Negative & 27 & $17(63.0)$ & $10(37.0)$ & \\
\hline Positive & 33 & $19(57.6)$ & $14(42.4)$ & \\
\hline Nuclear grade & & & & 0.191 \\
\hline $\mathrm{I}$ & 22 & $18(81.8)$ & $4(18.2)$ & \\
\hline II & 19 & $12(65.5)$ & $7(34.5)$ & \\
\hline III & 19 & $9(47.4)$ & $10(52.6)$ & \\
\hline Histology & & & & 0.203 \\
\hline Ductal carcinoma & 26 & $16(61.5)$ & $10(38.5)$ & \\
\hline Lobular carcinoma & 22 & $19(86.4)$ & $3(13.6)$ & \\
\hline Other & 12 & $1(8.30)$ & $11(91.7)$ & \\
\hline
\end{tabular}

${ }^{\mathrm{a}} \mathrm{P}<0.05$. T, tumor.

Technologies, Inc., Santa Clara, CA, USA) (35). A tumor was considered to be HER2-positive if the tissue specimen scored $\geq 3$ for the intensity of membrane staining in the tumor cells.

Statistical analysis. Data were analyzed using SPSS version 19.0 for Windows (IBM SPSS, Armonk, NY, USA). Student's t-tests and Fisher's exact tests were used for continuous and categorical variables, respectively. DFS rates periods following surgery were calculated using the Kaplan-Meier method, and the variation between survival curves was assessed using the log-rank test. Multivariate regression analysis was performed using the Cox proportional hazards model. Pearson correlation analysis was used to compare the associations between FBP1 and HIF-1 $\alpha$ expression levels. Values are presented as the mean \pm standard deviation. $\mathrm{P}<0.05$ was considered to indicate a statistically significant difference.

\section{Results}

Clinical data. Of the 60 tumor tissue samples, 36 (60\%) were luminal-type tumors (Table II), whereas 24 tissue samples (40\%) were basal-like tumors.

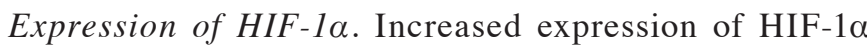
was primarily identified in the nuclei of tumor cells (Fig. 1A and B). Using a cut-off value of $\geq 5 \%$ of nuclei, 

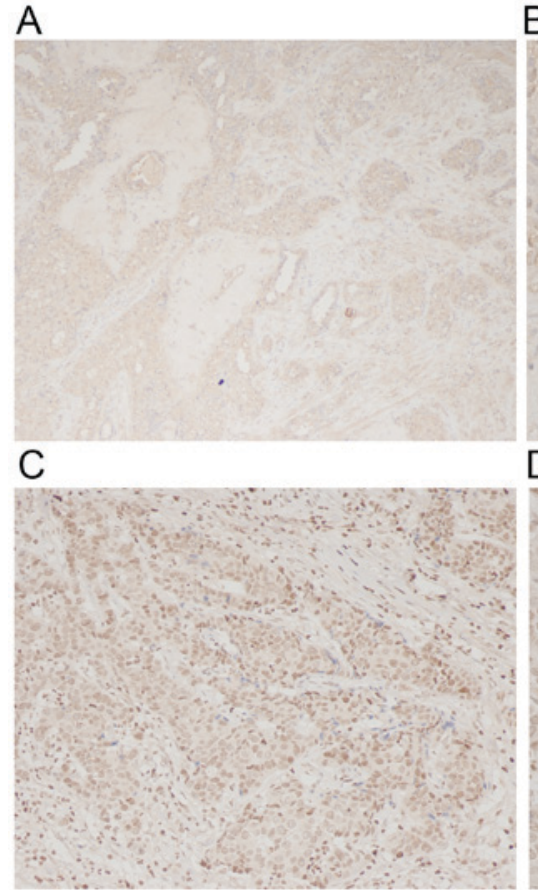

E

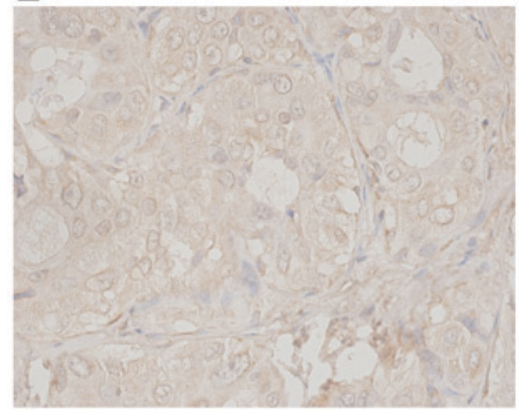

B

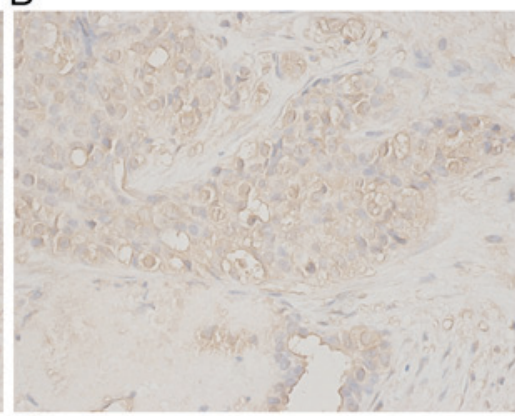

D

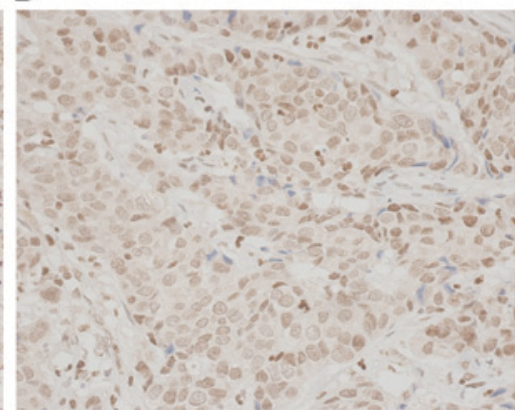

F

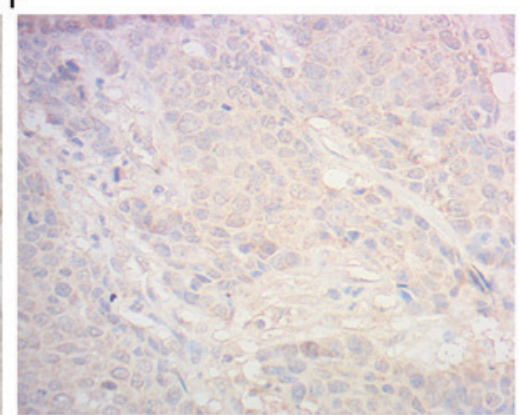

Figure 1. Immunohistochemical analysis of HIF-1 $\alpha$, CK5/6 and FBP1 expression levels in human breast cancer. (A) HIF-1 $\alpha$ expression was observed in invasive breast cancer (original magnification, x100). (B) High expression of HIF-1 $\alpha$ was detected in tumor cell nuclei (original magnification, x400). CK5/6 expression was observed within basal-like breast cancer tissue at (C) original magnification, $\mathrm{x} 200$ and (D) original magnification, $\mathrm{x} 400$. (E) The expression of FBP1 in luminal breast cancer tissue (original magnification, $\mathrm{x} 400$ ). (F) Low nuclear expression of FBP1 was detected in basal-like breast cancer tissue (original magnification, x400). HIF-1 $\alpha$, hypoxia-inducible factor-1 $\alpha$; FBP1, liver fructose-1,6-bisphophatase; CK5/6, cytokeratin 5/6.

positive HIF-1 $\alpha$ expression was identified in 20/60 (33.3\%) cases (Table III). Of these, 8 tumors (40\%) were luminal-type and 12 tumors $(60 \%)$ were basal-type. No association was observed between HIF-1 $\alpha$ expression levels and patient age $(\mathrm{P}=0.124)$, nuclear grade $(\mathrm{P}=0.732)$ or advanced tumor stage $(\mathrm{P}=0.411$; Table IV). Increased expression levels of HIF-1 $\alpha$ were associated with a high degree of lymph node metastasis $(\mathrm{P}=0.007$; Table IV).

Correlation between FBP1 expression levels and clinicopathological parameters in invasive breast carcinoma. Localization of FBP1 staining in the tissues was examined using conventional light microscopy. The levels of immunohistochemical staining in the nuclei (Fig. 1E and F) were divided into positive and negative FBP1 expression tumor groups. FBP1 was positive in 33/60 tumors (55\%; Table III). The majority of these tumors $(27 / 36 ; 75 \%)$ were of the luminal category. FBP1 in basal-like breast adenocarcinomas exhibited low or absent expression levels in $6 / 24(18.2 \%)$ cases $(\mathrm{P}=0.008)$. FBP1 expression was significantly correlated with small tumor size $(\mathrm{P}=0.012)$ and high nuclear grade $(\mathrm{P}=0.017$; Table IV $)$. No correlation was observed between patient age $(\mathrm{P}=0.475)$ and nodal status $(\mathrm{P}=0.864$; Table IV).

Correlation between the expression levels of HIF-1 $\alpha$ and $F B P 1$. The expression levels of CK5/6 were higher in the basal-like carcinoma tissues, whereas luminal cases exhibited low CK5/6 expression levels ( $\mathrm{P}=0.043$; Fig. $1 \mathrm{C}$ and D). In addition, increased HIF-1 $\alpha$ expression levels were positively correlated with low or absent expression levels of FBP1 in invasive breast carcinoma, and this aspect was statistically significant $(\mathrm{r}=-0.711 ; \mathrm{P}<0.001)$. In luminal breast carcinoma, increased HIF-1 $\alpha$ expression levels were significantly correlated with low or absent levels of FBP1 expression ( $r=-0.772$; $\mathrm{P}<0.001)$. In basal-like breast carcinoma, HIF-1 $\alpha$ expression levels were significantly negatively correlated with the levels of FBP1 expression $(r=-0.577 ; \mathrm{P}=0.003)$.

Survival analysis. In univariate survival analysis, patients with tumor tissues that did not express FBP1 had a significantly poorer DFS $(\mathrm{P}<0.001$; data not shown). There was a significant difference in the DFS of patients with any type of 
Table III. Immunohistochemical characteristics of cancer cells according to breast cancer phenotype.

\begin{tabular}{lccc}
\hline Antibodies & Total, $\mathrm{n}=60(\%)$ & Basal-like, $\mathrm{n}=24(40 \%)$ & Luminal, $\mathrm{n}=36(60 \%)$ \\
\hline HIF-1 $\alpha$ & & $28(70.0)$ \\
Negative & $40(66.7)$ & $12(30.0)$ & $8(40.0)$ \\
Positive & $20(33.3)$ & $12(60.0)$ & 0.056 \\
FBP1 & $27(45)$ & $18(66.7)$ & $9(33.3)$ \\
Negative & $33(55)$ & $6(18.2)$ & $27(81.8)$ \\
Positive & & & $36(100.0)$ \\
CK5/6 & $36(60)$ & $0(0.0)$ & $0.008^{\mathrm{a}}$ \\
Negative & $24(40)$ & $24(100.0)$ & $0.043^{\mathrm{a}}$ \\
Positive & & & $0.0)$ \\
\hline
\end{tabular}

${ }^{a} \mathrm{P}<0.05$ indicates a statistically significant difference. HIF-1 $1 \alpha$, hypoxia-inducible factor- $1 \alpha$; FBP1, liver fructose-1,6-bisphophatase; CK5/6, cytokeratin $5 / 6$.

Table IV. Correlation between the expression levels of metabolism genes and clinicopathological factors.

\begin{tabular}{|c|c|c|c|c|c|c|}
\hline \multirow[b]{2}{*}{ Parameters } & \multicolumn{3}{|c|}{$\mathrm{HIF}-1 \alpha$} & \multicolumn{3}{|c|}{ FBP1 } \\
\hline & $(-)$ & $(+)$ & $\mathrm{P}$-value & $(-)$ & $(+)$ & P-value \\
\hline Age, years & & & 0.124 & & & 0.475 \\
\hline$\leq 35$ & 10 & 1 & & 13 & 7 & \\
\hline$>35$ & 34 & 15 & & 14 & 26 & \\
\hline Nuclear grade & & & 0.732 & & & $0.017^{\mathrm{a}}$ \\
\hline $\mathrm{I} / \mathrm{II}$ & 28 & 13 & & 10 & 31 & \\
\hline III & 16 & 3 & & 17 & 2 & \\
\hline $\mathrm{T}$ stage & & & 0.411 & & & $0.012^{\mathrm{a}}$ \\
\hline $\mathrm{T} 1$ & 25 & 5 & & 6 & 24 & \\
\hline $\mathrm{T} 2-3$ & 19 & 11 & & 21 & 9 & \\
\hline $\mathrm{N}$ stage & & & $0.007^{\mathrm{a}}$ & & & 0.864 \\
\hline No & 25 & 2 & & 6 & 21 & \\
\hline $\mathrm{N} 1-3$ & 19 & 14 & & 21 & 12 & \\
\hline
\end{tabular}

${ }^{a} \mathrm{P}<0.05$ indicates a statistically significant difference. (+) Indicates positive and (-) indicates negative immunohistochemical staining HIF-1 $\alpha$, hypoxia-inducible factor- $1 \alpha$; FBP1, liver fructose-1,6-bisphophatase; CK5/6, cytokeratin 5/6; T, tumor; N, node.

breast carcinoma, when stratified by the levels of FBP1 expression ( $\mathrm{P}<0.001$; Fig. 2A and B). Patients with FBP1-positive basal-like breast carcinomas had a significantly longer DFS, compared with patients with FBP1-negative basal-like breast carcinomas $(\mathrm{P}<0.001$; Fig. 2B). Significant differences in DFS were observed among the luminal subtypes $(\mathrm{P}<0.001)$, and when basal-like carcinoma types were stratified according to HIF-1 $\alpha$ expression levels $(\mathrm{P}<0.001)$. HIF-1 $\alpha$-positive tumor tissue samples were significantly associated with a shorter DFS $(\mathrm{P}<0.001)$, compared with HIF-1 $\alpha$-negative tissue samples, in patients with invasive breast cancer (Fig. 3A and B). Node-positive patients exhibited a shorter DFS, as compared with node-negative patients $(\mathrm{P}=0.001$; Fig. 4; Table V). In a multivariate Cox regression model, FBP1 and tumor size were identified as independent prognostic factors (Table VI).

\section{Discussion}

Livasy et al (36) reported that the most frequent immunophenotype of basal-like breast adenocarcinoma consists of negative expression of ER and HER2, and positive expression of $\mathrm{CK} 5 / 6, \mathrm{CK} 8 / 18$ and vimentin. CK5/6 is considered to be the most common basal marker of metabolism-associated adaptation in basal-like breast cancer (37). The results of the present study revealed an association between low expression levels of FBP1 and CK5/6 positivity.

In the current study, increased HIF-1 $\alpha$ expression levels did not differ significantly between luminal and basal-like breast carcinoma. In these forms of breast carcinoma, expression of HIF-1 $\alpha$ was primarily detected in the tumor cell nuclei. In addition, the overexpression of HIF-1 $\alpha$ was detected in 

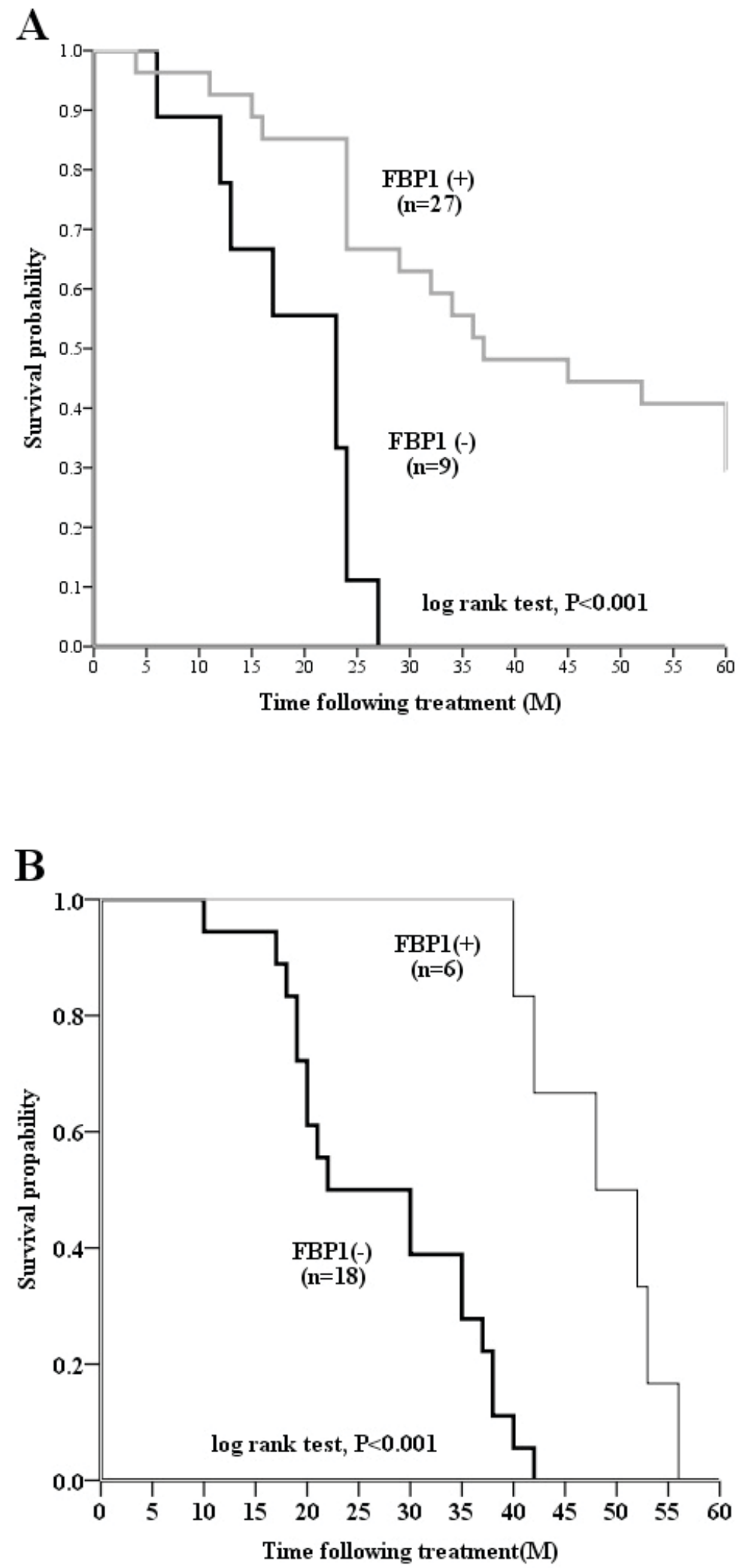

Figure 2. FBP1 status in patients with breast cancer. (A) Kaplan-Meier curves of disease-free survival in patients with luminal breast cancer. (B) Kaplan-Meier curves of disease-free survival in patients with basal-like breast cancer cell. P-values were calculated according to the log-rank test. FBP1, liver fructose-1,6-bisphosphatase.

$20 / 60(33.3 \%)$ invasive breast cancer tissues, when this was defined as $\geq 5 \%$ nuclear HIF- $1 \alpha$ immunoreactivity. Yamamoto et al (38) observed increased HIF-1 $\alpha$ expression levels in invasive breast cancer. A number of studies have suggested that
HIF-1 $\alpha$ protein overexpression is a marker of poor prognosis in patients with primary breast cancer $(39,40)$. In the current study, total HIF-1 $\alpha$ expression was negatively correlated with DFS. There is an urgent requirement to predict the factors 


\section{A}

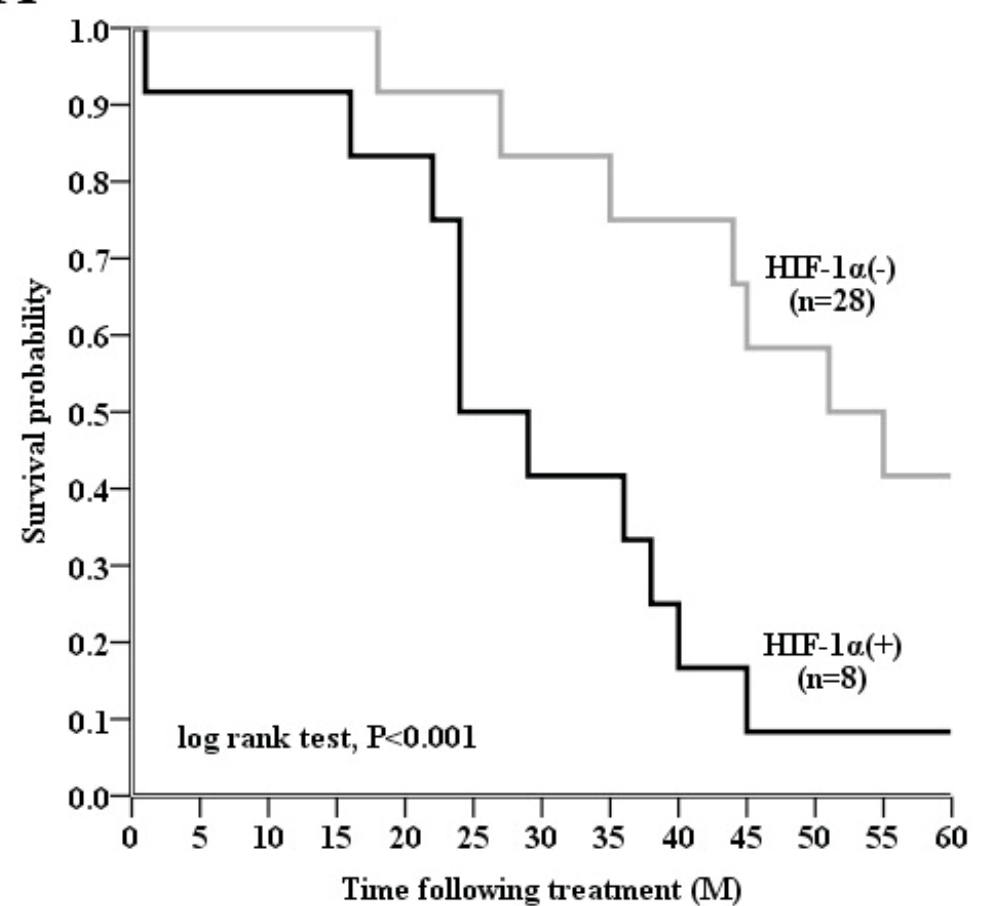

B

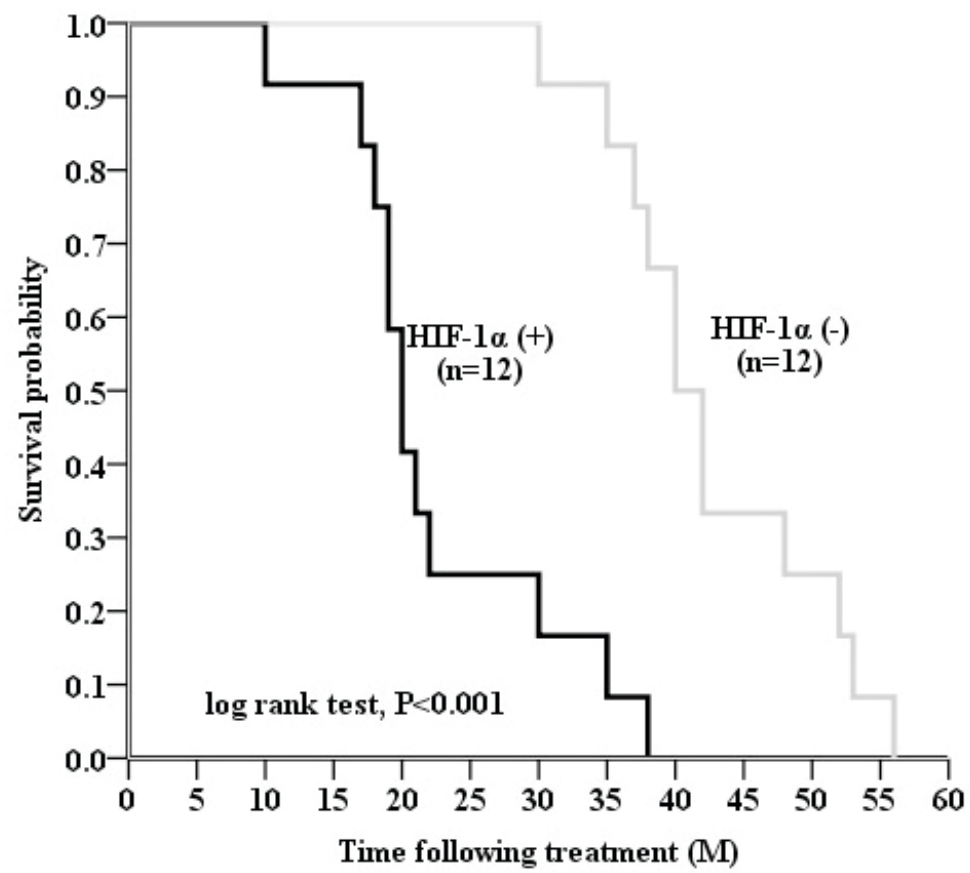

Figure 3. HIF-1 $\alpha$ status in patients with breast cancer. (A) Kaplan-Meier curves of disease-free survival in patients with luminal breast cancer. (B) Kaplan-Meier curves of disease-free survival in patients with basal-like breast cancer. P-values were calculated according to the log-rank test. HIF-1 $\alpha$, hypoxia-inducible factor- $1 \alpha$.

that may be associated with HIF-1 $\alpha$ expression in clinical tissue samples. The present study demonstrated associations between HIF-1 $\alpha$ expression levels, and lymph node metastasis and FBP1 expression.

A significant association between positive node status and intense, diffuse HIF-1 $\alpha$ staining in breast tumor tissues was observed during the current study, and HIF-1 $\alpha$ expression levels were markedly higher in lymph node metastatic tumors.
These results are concordant with the findings of previous studies $(40,41)$, which demonstrated that the expression levels of HIF-1 $\alpha$ were high in the majority of patients with positive axilla lymph nodes and served as a predictor of poor prognosis. Furthermore, Schoppmann et al (42) identified a significant association between HIF-1 $\alpha$ expression and the degree of peritumoral lymphangiogenesis in patients with breast cancer. Consequently, this finding suggests that HIF- $1 \alpha$-positive 


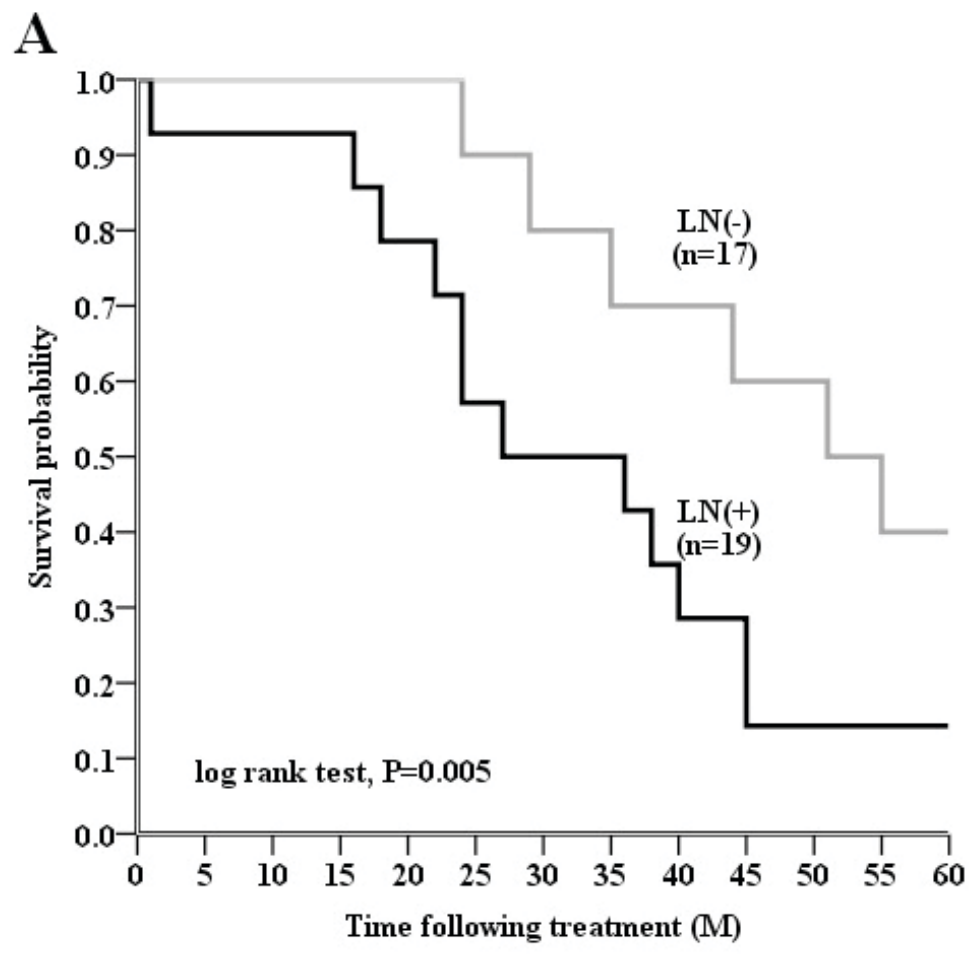

B

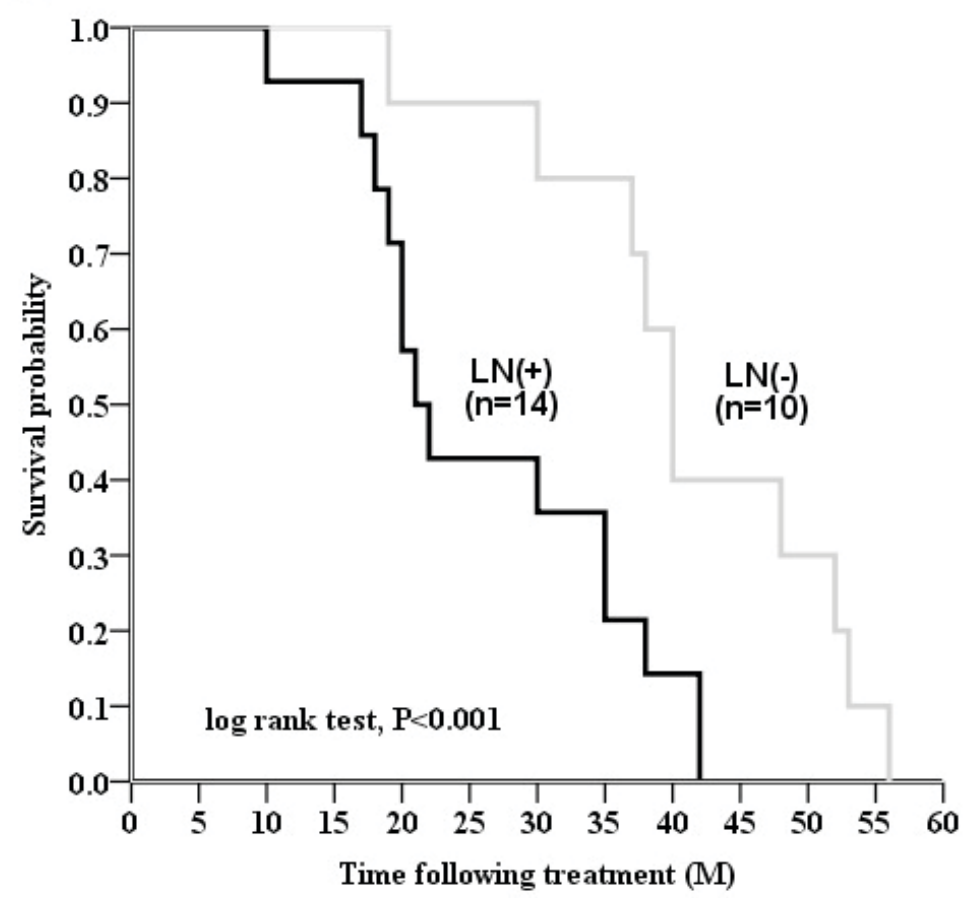

Figure 4. LN status in breast cancer. (A) Kaplan-Meier curves of disease-free survival in patients with luminal breast cancer. (B) Kaplan-Meier curves of disease-free survival in patients with basal-like breast cancer cell. P-values were calculated according to the log-rank test. LN, lymph node.

tumors possess a high degree of lymph node metastasis, as compared with HIF-1 $\alpha$-negative tumors.

No significant association between HIF-1 $\alpha$ expression and large tumors and a more advanced nuclear grade was observed in the present study. Conversely, Kronblad et al (43) noted a significant positive correlation between these factors, particularly in tumors with diameters $>5 \mathrm{~cm}$. It has been hypothesized that the levels of HIF-1 $\alpha$ expression increase with tumor growth, as large tumors are generally more hypoxic, compared with those of a small size (38). The correlation between HIF-1 $\alpha$ expression and nuclear grade also remains to be established. Bos et al (34) demonstrated that increased levels of HIF-1 $\alpha$ expression were positively associated with nuclear grade. Kronblad et al (43) evaluated 564 patients and observed a positive correlation between increased histological grade and HIF- $1 \alpha$ expression levels. It is established that hypoxia induces genetic alterations in tumor cells 
Table V. Univariate analysis of clinicopathological and immunohistological results and disease-free survival.

\begin{tabular}{|c|c|c|c|}
\hline \multirow[b]{2}{*}{ Parameters } & \multirow{2}{*}{$\begin{array}{c}\text { Number of } \\
\text { patients }(n=60)\end{array}$} & \multicolumn{2}{|c|}{ Disease-free survival } \\
\hline & & Mean survival, months (95\% CI) & P-value \\
\hline T stage & & & $0.013^{\mathrm{a}}$ \\
\hline $\mathrm{T} 1$ & 23 & $40.9(35.4-46.4)$ & \\
\hline $\mathrm{T} 2-3$ & 37 & $29.1(24.7-33.5)$ & \\
\hline $\mathrm{N}$ stage & & & $<0.001^{\mathrm{a}}$ \\
\hline No & 27 & $41.9(36.4-47.4)$ & \\
\hline N1-3 & 33 & $26.8(23.1-30.6)$ & \\
\hline Age & & & 0.124 \\
\hline$\leq 35$ & 11 & $28.3(22.1-33.7)$ & \\
\hline$>35$ & 49 & $49.5(41.6-55.8)$ & \\
\hline Histological grade & & & 0.667 \\
\hline $\mathrm{I} / \mathrm{II}$ & 41 & $41.5(35.4-44.7)$ & \\
\hline III & 19 & $31.5(26.1-35.1)$ & \\
\hline HIF- $1 \alpha$ & & & $<0.001^{\mathrm{a}}$ \\
\hline Negative & 40 & $40.5(36.6-44.4)$ & \\
\hline Positive & 20 & $19.8(16.7-22.9)$ & \\
\hline FBP1 & & & $<0.001^{\mathrm{a}}$ \\
\hline Negative & 27 & $23.6(20.0-27.3)$ & \\
\hline Positive & 33 & $41.8(37.3-46.2)$ & \\
\hline
\end{tabular}

${ }^{\mathrm{a}} \mathrm{P}<0.05$ indicates a statistically significant difference. HIF-1 $\alpha$, hypoxia-inducible factor-1 $\alpha$; FBP1, liver fructose-1,6-bisphophatase; CK5/6, cytokeratin $5 / 6$; CI, confidence interval; $\mathrm{T}$, tumor; $\mathrm{N}$, node.

Table VI. Multivariate analysis of prognostic markers.

\begin{tabular}{lccc}
\hline Variable & Odds ratio & $95 \%$ CI & P-value \\
\hline FBP1 (-) vs. (+) & 0.289 & $0.103-0.734$ & $0.010^{\mathrm{a}}$ \\
HIF-1 $\alpha$ (-) vs. (+) & 1.012 & $0.407-2.395$ & 0.797 \\
T-stage (<2 cm) vs. (>2 cm) & 1.672 & $1.158-3.310$ & $0.012^{\mathrm{a}}$ \\
LN (-) vs. (+) & 1.158 & $0.634-2.163$ & 0.613 \\
\hline
\end{tabular}

${ }^{a} \mathrm{P}<0.05$ indicates a statistically significant difference. (+) Indicates positive and (-) indicates negative immunohistochemical staining. HIF-1 $\alpha$, hypoxia-inducible factor-1 $\alpha$; FBP1, liver fructose-1,6-bisphosphatase; CK5/6, cytokeratin 5/6; LN, lymph node; CI, confidence interval.

that allow them to adapt to a hypoxic environment (44-46). Such genetic alterations also induce morphological changes in tumor cells and their nuclei. No significant correlation between HIF-1 $\alpha$ expression levels and nuclear grade was observed in the present study, which may be due to the limited sample size and a majority of the HIF-1 $\alpha$ positive patients within the basal-like group.

To the best of our knowledge, the current study demonstrated for the first time that FBP1 expression levels correlate with the clinicopathological characteristics of tumors in patients with basal-like breast carcinoma. FBP1 localizes to the nuclei of proliferating cells $(47,48)$ and is recognized to be important for the regulation of gluconeogenesis $(49,50)$. The FBP1 gene is also expressed in certain cancer cells; however, its expression levels are reduced by comparison with non-malignant tissues $(27,29)$. Bhide (51) also observed that the activities of gluconeogenic enzymes were lowest in tumor tissues. The loss of FBP activity in tumors may therefore result in loss of the gluconeogenic capacity of malignant tissues. In the present study, FBP1 expression levels decreased progressively in basal-like breast carcinoma, as compared with luminal cell lines; FBP1 levels are correlated with nuclear grade and tumor stage, and are indicative of extended DFS. These results are concordant with an earlier study from Liu et al (27), which observed that high FBP1 expression levels in cells from patients with gastric carcinoma are predictive of survival. The significant positive association between FBP1 and DFS may occur as FBP1 inhibits HIF-1 $\alpha$ and glycolytic metabolism (28). Alternatively, this effect may be due to the 
downstream targets of HIF-1 $\alpha$, carbonic anhydrase IX and glucose transporter 1, being inhibited by FBP1 (28).

The association between HIF-1 $\alpha$ and FBP1 expression was also examined in the current study, revealing negative correlations between HIF-1 $\alpha$ and FBP1 expression levels in basal-like breast carcinoma tissues. This result is supported by a study from Li et al (28), which observed the same correlation between these two parameters in renal cell carcinoma. It is established that the HIF-1 $\alpha$ increases the level of glycolysis, and the stability and signaling of this protein is primarily involved in glucose metabolism, neovascularization and survival $(52,53)$. As a result, the gluconeogenic process is inhibited and the levels of FBP1-limited enzyme expression are reduced (28). Consequently, the findings of the present study suggest that changes in the expression of FBP1 may result in the differential expression of HIF-1 $\alpha$, and FBP1 may be a target of HIF-1 $\alpha$ in basal-like breast carcinoma.

In the present study, the effects of adjuvant (chemotherapy or hormone) treatment on survival, and its interactions with the expression levels of HIF-1 $\alpha$ and FBP1 were not examined due to the limited number of patients in each subgroup. Further studies with a larger sample size are therefore required to examine this effect.

In conclusion, the results of the current study suggest that FBP1 is negatively correlated with DFS in patients with basal-like breast carcinoma, potentially due to the expression of FBP1 inhibiting the nuclear levels of HIF-1 $\alpha$. Therefore, further study of the expression levels of FBP1 using immunoprecipitation analysis may aid understanding of the interaction between FBP1 and HIF-1 $\alpha$ in breast cancer. Furthermore, it may be valuable to examine the FBP1 status of patients with breast cancer, to enable the selection of novel therapeutic strategies for breast cancer in the future.

\section{References}

1. Vaupel P, Schlenger K, Knoop C and Höckel M: Oxygenation of human tumors: Evaluation of tissue oxygen distribution in breast cancers by computerized $\mathrm{O} 2$ tension measurements. Cancer Res 51: 3316-3322, 1991.

2. Vaupel P: The role of hypoxia-induced factors in tumor progression. Oncologist 9 (Suppl 5): S10-S17, 2004.

3. Fisher ER, Anderson S, Redmond C and Fisher B: Pathologic findings from the national surgical adjuvant breast project protocol B-06. 10-year pathologic and clinical prognostic discriminants. Cancer 71: 2507-2514, 1993.

4. Hockel M and Vaupel P: Tumor hypoxia: Definitions and current clinical, biologic, and molecular aspects. J Natl Cancer Inst 93: 266-276, 2001

5. Garcia S, Dalès JP, Charafe-Jauffret E, Carpentier-Meunier S, Andrac-Meyer L, Jacquemier J, Andonian C, Lavaut MN, Allasia C, Bonnier P and Charpin C: Poor prognosis in breast carcinomas correlates with increased expression of targetable CD146 and c-Met and with proteomic basal-like phenotype. Hum Pathol 38: 830-841, 2007.

6. Kallergi G, Markomanolaki H, Giannoukaraki V, Papadaki MA, Strati A, Lianidou ES, Georgoulias V, Mavroudis D and Agelaki S: Hypoxia-inducible factor-1alpha and vascular endothelial growth factor expression in circulating tumor cells of breast cancer patients. Breast cancer Res 11: R84, 2009.

7. Karlin KL, Mondal G, Hartman JK, Tyagi S, Kurley SJ, Bland CS, Hsu TY, Renwick A, Fang JE, Migliaccio I, et al: The oncogenic STP axis promotes triple-negative breast cancer via degradation of the REST tumor suppressor. Cell Rep 9: 1318-1332, 2014.

8. Gleadle JM and Ratcliffe PJ: Induction of hypoxia-inducible factor-1, erythropoietin, vascular endothelial growth factor, and glucose transporter-1 by hypoxia: Evidence against a regulatory role for Src kinase. Blood 89: 503-509, 1997.
9. Price BD and Calderwood SK: Gadd45 and Gadd 153 messenger RNA levels are increased during hypoxia and after exposure of cells to agents which elevate the levels of the glucose-regulated proteins. Cancer Res 52: 3814-3817, 1992.

10. Moulder JE and Rockwell S: Tumor hypoxia: Its impact on cancer therapy. Cancer Metastasis Rev 5: 313-341, 1987.

11. Giaccia AJ: Hypoxic stress proteins: Survival of the Fittest. Semin Radiat Oncol 6: 46-58, 1996.

12. Kunz M and Ibrahim SM: Molecular responses to hypoxia in tumor cells. Mol Cancer 2: 23, 2003.

13. Harris AL: Hypoxia-a key regulatory factor in tumour growth. Nat Rev Cancer 2: 38-47, 2002.

14. Semenza GL: HIF-1, O(2), and the 3 PHDs: How animal cells signal hypoxia to the nucleus. Cell 107: 1-3, 2001.

15. Jaakkola P, Mole DR, Tian YM, Wilson MI, Gielbert J, Gaskell SJ, von Kriegsheim A, Hebestreit HF, Mukherji M, Schofield CJ, et al: Targeting of HIF-alpha to the von Hippel-Lindau ubiquitylation complex by O2-regulated prolyl hydroxylation. Science 292: 468-472, 2001.

16. Semenza GL: Hypoxia, clonal selection, and the role of HIF-1 in tumor progression. Crit Rev Biochem Mol Biol 35: 71-103, 2000.

17. Kreike B, van Kouwenhove M, Horlings H, Weigelt B, Peterse H, Bartelink $\mathrm{H}$ and van de Vijver MJ: Gene expression profiling and histopathological characterization of triple-negative/basal-like breast carcinomas. Breast Cancer Res 9: R65, 2007.

18. Rakha EA, Elsheikh SE, Aleskandarany MA, Habashi HO, Green AR, Powe DG, El-Sayed ME, Benhasouna A, Brunet JS, Akslen LA, et al: Triple-negative breast cancer: Distinguishing between basal and nonbasal subtypes. Clin Cancer Res 15: 2302-2310, 2009.

19. Tan EY, Yan M, Campo L, Han C, Takano E, Turley H, Candiloro I, Pezzella F, Gatter KC, Millar EK, et al: The key hypoxia regulated gene CAIX is upregulated in basal-like breast tumours and is associated with resistance to chemotherapy. Br J Cancer 100: 405-411, 2009.

20. Tsuda H, Takarabe T, Hasegawa F, Fukutomi T and Hirohashi S: Large, central acellular zones indicating myoepithelial tumor differentiation in high-grade invasive ductal carcinomas as markers of predisposition to lung and brain metastases. Am J Surg Pathol 24: 197-202, 2000.

21. Riva C, Chauvin C, Pison C and Leverve X: Cellular physiology and molecular events in hypoxia-induced apoptosis. Anticancer Res 18: 4729-4736, 1998.

22. Vaupel P, Kallinowski F and Okunieff P: Blood flow, oxygen and nutrient supply, and metabolic microenvironment of human tumors: A review. Cancer Res 49: 6449-6465, 1989.

23. Semenza GL, Roth PH, Fang HM and Wang GL: Transcriptional regulation of genes encoding glycolytic enzymes by hypoxia-inducible factor 1. J Biol Chem 269: 23757-23763, 1994.

24. Mizunuma $\mathrm{H}$ and Tashima Y: Fructose-1,6-biphosphatase of the small intestine. Purification and comparison with liver and muscle fructose-1,6-bisphosphatases. J Biochem 84: 327-336, 1978.

25. Tillmann $\mathrm{H}$ and Eschrich $\mathrm{K}$ : Isolation and characterization of an allelic cDNA for human muscle fructose-1,6-bisphosphatase. Gene 212: 295-304, 1998.

26. Tejwani GA: Regulation of fructose-bisphosphatase activity. Adv Enzymol Relat Areas Mol Biol 54: 121-194, 1983.

27. Liu X, Wang X, Zhang J, Lam EK, Shin VY, Cheng AS, Yu J, Chan FK, Sung JJ and Jin HC: Warburg effect revisited: An epigenetic link between glycolysis and gastric carcinogenesis. Oncogene 29: 442-450, 2010

28. Li B, Qiu B, Lee DS, Walton ZE, Ochocki JD, Mathew LK, Mancuso A, Gade TP, Keith B, Nissim I and Simon MC: Fructose-1,6-bisphosphatase opposes renal carcinoma progression. Nature 513: 251-255, 2014.

29. Bigl M, Jandrig B, Horn LC and Eschrich K: Aberrant methylation of human L- and M-fructose 1,6-bisphosphatase genes in cancer. Biochem Biophys Res Commun 377: 720-724, 2008.

30. Viale G: Histopathology of primary breast cancer 2003. Breast 12: 391-396, 2003.

31. Elston CW and Ellis IO: Pathological prognostic factors in breast cancer. I. The value of histological grade in breast cancer: Experience from a large study with long-term follow-up. Histopathology 41: 154-161,2002.

32. Carlson RW: NCCN breast cancer clinical practice guidelines in oncology: An update. J Natl Compr Canc Netw 1 (Suppl 1): S61-S63, 2003. 
33. Zhou M, Zhao Y, Ding Y, Liu H, Liu Z, Fodstad O, Riker AI, Kamarajugadda S, Lu J, Owen LB, et al: Warburg effect in chemosensitivity: Targeting lactate dehydrogenase-A re-sensitizes taxol-resistant cancer cells to taxol. Mol Cancer 9: 33, 2010

34. Bos R, van der Groep P, Greijer AE, Shvarts A, Meijer S, Pinedo HM, Semenza GL, van Diest PJ and van der Wall E: Levels of hypoxia-inducible factor-1alpha independently predict prognosis in patients with lymph node negative breast carcinoma. Cancer 97: 1573-1581, 2003.

35. Jacobs TW, Gown AM, Yaziji H, Barnes MJ and Schnitt SJ: Specificity of HercepTest in determining HER-2/neu status of breast cancers using the United States Food and Drug Administration-approved scoring system. J Clin Oncol 17: 1983-1987, 1999.

36. Livasy CA, Karaca G, Nanda R, Tretiakova MS, Olopade OI, Moore DT and Perou CM: Phenotypic evaluation of the basal-like subtype of invasive breast carcinoma. Mod Pathol 19: 264-271, 2006.

37. Nielsen TO, Hsu FD, Jensen K, Cheang M, Karaca G, Hu Z Hernandez-Boussard T, Livasy C, Cowan D, Dressler L, et al: Immunohistochemical and clinical characterization of the basal-like subtype of invasive breast carcinoma. Clin Cancer Res 10: 5367-5374, 2004

38. Yamamoto Y, Ibusuki M, Okumura Y, Kawasoe T, Kai K, Iyama $\mathrm{K}$ and Iwase $\mathrm{H}$ : Hypoxia-inducible factor 1alpha is closely linked to an aggressive phenotype in breast cancer. Breast Cancer Res Treat 110: 465-475, 2008.

39. Dales JP, Garcia S, Meunier-Carpentier S, Andrac-Meyer L, Haddad O, Lavaut MN, Allasia C, Bonnier P and Charpin C: Overexpression of hypoxia-inducible factor HIF-1alpha predicts early relapse in breast cancer: Retrospective study in a series of 745 patients. Int J Cancer 116: 734-739, 2005.

40. Schindl M, Schoppmann SF, Samonigg H, Hausmaninger H, Kwasny W, Gnant M, Jakesz R, Kubista E, Birner P and Oberhuber G; Austrian Breast and Colorectal Cancer Study Group: Overexpression of hypoxia-inducible factor 1alpha is associated with an unfavorable prognosis in lymph node-positive breast cancer. Clin Cancer Res 8: 1831-1837, 2002.

41. Giatromanolaki A, Koukourakis MI, Simopoulos C, Polychronidis A, Gatter KC, Harris AL and Sivridis E: c-erbB-2 related aggressiveness in breast cancer is hypoxia inducible factor-1alpha dependent. Clin Cancer Res 10: 7972-7977, 2004.
42. Schoppmann SF, Fenzl A, Schindl M, Bachleitner-Hofmann T, Nagy K, Gnant M, Horvat R, Jakesz R and Birner P: Hypoxia inducible factor-1alpha correlates with VEGF-C expression and lymphangiogenesis in breast cancer. Breast Cancer Res Treat 99: $135-141,2006$.

43. Kronblad A, Jirstrom K, Rydén L, Nordenskjöld B and Landberg G: Hypoxia inducible factor-1alpha is a prognostic marker in premenopausal patients with intermediate to highly differentiated breast cancer but not a predictive marker for tamoxifen response. Int J Cancer 118: 2609-2616, 2006.

44. Semenza GL: HIF-1 and tumor progression: Pathophysiology and therapeutics. Trends Mol Med 8 (4 Suppl): S62-S67, 2002.

45. Zhong H, De Marzo AM, Laughner E, Lim M, Hilton DA, Zagzag D, Buechler P, Isaacs WB, Semenza GL and Simons JW: Overexpression of hypoxia-inducible factor 1alpha in common human cancers and their metastases. Cancer Res 59: 5830-5835, 1999.

46. Page EL, Robitaille GA, Pouysségur J and Richard DE: Induction of hypoxia-inducible factor-1alpha by transcriptional and translational mechanisms. J Biol Chem 277: 48403-48409, 2002.

47. Gizak A, Rakus D and Dzugaj A: Nuclear localization of fructose 1,6-bisphosphatase in smooth muscle cells. J Mol Histol 36: 243-248, 2005

48. Mamczur P, Mazurek J and Rakus D: Ubiquitous presence of gluconeogenic regulatory enzyme, fructose-1,6-bisphosphatase, within layers of rat retina. Cell Tissue Res 341: 213-221, 2010.

49. Nordlie RC, Foster JD and Lange AJ: Regulation of glucose production by the liver. Annu Rev Nutr 19: 379-406, 1999.

50. Radziuk J and Pye S: Hepatic glucose uptake, gluconeogenesis and the regulation of glycogen synthesis. Diabetes Metab Res Rev 17: 250-272, 2001.

51. Bhide SV: Enzyme studies on tumour cell suspensions. Br J Cancer 24: 869-874, 1970.

52. Pouysségur J, Dayan F and Mazure NM: Hypoxia signalling in cancer and approaches to enforce tumour regression. Nature 441: 437-443, 2006.

53. Ryan HE, Poloni M, McNulty W, Elson D, Gassmann M, Arbeit JM and Johnson RS: Hypoxia-inducible factor-1alpha is a positive factor in solid tumor growth. Cancer Res 60: 4010-4015, 2000 . 